\title{
Infliximab in the treatment of Crohn's disease
}

\author{
Gilberto Poggioli \\ Silvio Laureti \\ Massimo Campieri* \\ Filippo Pierangeli \\ Paolo Gionchetti* \\ Federica Ugolini \\ Lorenzo Gentilini \\ Piero Bazzi \\ Fernando Rizzello* \\ Maurizio Coscia \\ General Surgery Department; \\ Policlinico S. Orsola; University of \\ Bologna, Italy; *Internal Medicine \\ Department; Policlinico S. Orsola; \\ University of Bologna, Italy
}

Correspondence: Gilberto Poggioli Unità di Chirurgia, Ospedale S. Orsola, Via Massarenti, 9, 40138 Bologna, Italy

Tel +3905 I63647I8

Fax +3905 I636 4823

Email poggioli@med.unibo.it

\begin{abstract}
The recent introduction of infliximab, a chimeric monoclonal antibody against tumor necrosis factor- $\alpha$, has greatly modified the treatment of Crohn's disease (CD). Data from the literature show encouraging results after intravenous infusion both for closure of intestinal or perianal fistulas and for induction and maintenance of remission in patients with moderate to severe intestinal disease unresponsive to other treatments. However, some contraindications such as fibrostenosing CD and sepsis have been identified. In addition, the data on long-term outcomes and safety is still limited. Our initial experience showed that in selected cases local injection of infliximab is effective in the treatment of complex perianal disease offering the possibility of using such treatment even in small bowel obstructing disease with minimal systemic effects. This paper analyzes the state of the use of both intravenous and local injection of infliximab in patients with CD.
\end{abstract}

Keywords: infliximab, Crohn's disease, perianal fistulas, local injection.

\section{Pharmacology/mode of action}

The pathogenetic mechanisms that underlie the chronic intestinal inflammation of Crohn's disease (CD) have been progressively classified since the early 1990s. The improved knowledge of systemic and local inflammatory cascade allowed the identification of key mediators of inflammation. Pharmacologic research was addressed then towards specific biologic drugs interfering with this cascade (Hanauer 2003).

Infliximab is a genetically engineered immunoglobulin 1 (IgG1) murine-human chimeric monoclonal antibody (Sandborn and Hanauer 1999), which binds with high affinity to both the soluble and the transmembrane forms of human tumor necrosis factor- $\alpha$ (TNF- $\alpha$ ). Seventy-five percent of the antibody consists of human IgG1 Fc fragment, the remainder being of murine origin. It is the murine part of the antibody which can bind human TNF, while the human tract is very important in order to decrease immunogenicity and for preserving functional immune capacity.

TNF is a key proinflammatory cytokine in CD and in other inflammatory conditions such as rheumatoid arthritis (Siddiqui and Scott 2005), psoriasis (Kleyn and Griffiths 2006) and spondylarthropaty (Robinson and Keating 2005) and plays a central role in amplification of the inflammatory process.

TNF- $\alpha$ is produced mainly by activated macrophages and Tymphocytes, among other cells, induces other proinflammatory cytokines including interleukin-1 (IL-1) and IL-6 and enhances leukocyte migration by inducing expression of adhesion molecules by endothelial cells and leukocytes. It activates leukocytes and induces acute-phase reactants and metalloproteinases; it also inhibits apoptosis of inflammatory cells. The number of cells producing TNF greatly increased in the lamina propria of the bowel in patients with CD (Reinecker et al 1993; Breese et al 1994) and increased concentrations of TNF have been found in the stools of children with CD (Nicholls et al 1993).

The mechanism of action of infliximab is still not well understood. Its main activity consists in neutralization of soluble and transmembrane TNF (Mitoma et al 2005) in 
other biological drugs in comparision with etanercept which can bind only the soluble form of TNF and is therefore less efficient than infliximab. Research has underlined that the role of infliximab couldn't be only in blocking TNF activity but includes other important functions such as: the modulation of TNF producing cells by complement fixation (van den Brande et al 2005); antibody-dependent cytotoxicity and apoptosis of T lymphocytes and monocytes caused by the IgG1 Fc portion of the antibody (Scallon et al 1995; Sandborn and Hanauer 1999; Papadakis and Targan 2000); and the down-regulation of other proinflammatory cytokines. These activities can be demonstrated in biopsy samples obtained from patients treated with this drug and by the reduction of cytokine's concentration in their serum (Markham and Lamb 2000).

Infliximab can also reduce the number of inflammatory cells in the sites of inflammation because it decreases the levels of chemokines and endothelial adhesion molecules, however it does not produce a generalized suppression of cellular immune function (Cornillie et al 2001).

\section{Intravenous treatment}

Current indications for treatment with infliximab are refractory luminal $\mathrm{CD}$, steroid-dependent $\mathrm{CD}$, and refractory fistulizing CD. Such therapy has been showed to be effective even in systemic manifestation of CD, ankylosing spondylitis (Jois et al 2006), pyoderma gangrenosum (Brooklyn et al 2006), chronic uveitis (Hale and Lightman 2006), and metastatic CD (Rispo et al 2004).

\section{Refractory luminal CD}

The initial positive experience with infliximab in a single patient with CD (Derkx et al 1993) led to an open pilot dose-finding study with 10 patients using $10 \mathrm{mg} / \mathrm{kg}$ or $20 \mathrm{mg} /$ $\mathrm{kg}$ doses. Targan and colleagues (1997) conduced then a placebo controlled trial at doses of $5 \mathrm{mg} / \mathrm{kg}, 10 \mathrm{mg} / \mathrm{kg}$, and $20 \mathrm{mg} / \mathrm{kg}$ in 108 patients with moderately to severely active CD refractory to conventional therapy. After 4 weeks of treatment, both clinical response (primary endpoint) and clinical remission rates were significantly higher in patients receiving infliximab than placebo recipients (65\% vs $17 \%$ and $33 \%$ vs $4 \%$, respectively). These patients were then included in a second study, the first on maintenance evaluation, and were treated with $10 \mathrm{mg} / \mathrm{kg}$ or placebo at 0 , $12,20,28$, and 36 weeks. A total of $53 \%$ maintained remission but the majority of patients relapsed between 44 and 48 weeks. Based on these findings the Authors concluded that the duration of benefits for infliximab is approximately 8 weeks.

These results lead to a more comprehensive evaluation of the clinical benefit of long term maintenance treatment

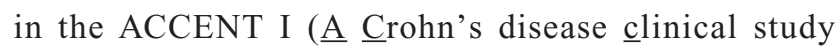
evaluating infliximab in a new long term treatment regimen) study (Hanauer et al 2002). In this study, repeated treatment with $5 \mathrm{mg}$ or $10 \mathrm{mg}$ of infliximab was effective in maintaining remission in patients who had responded to the initial treatment with no difference between the two dosages ( $58 \%$ of 573 patients responded by 2 weeks of treatment; at week 10, 69\% responded and 42\% reached remission). A significantly higher number of patients receiving infliximab were in clinical remission both at week 30 and at week 54 . The study showed that patients will need maintenance therapy after a loading dose of $5 \mathrm{mg}$ at 0,2 , and 6 weeks even when treated with concomitant immunosuppression. In the absence of maintainance therapy, 37\% will relapse by 12 weeks.

Of note, in the ACCENT 1 study, a lower rate of diseaserelated hospitalizations occurred in $5 \mathrm{mg} / \mathrm{kg}$ and $10 \mathrm{mg} / \mathrm{kg}$ mainteinance treatment groups (23\% and 24\% respectively vs $38 \%$ in patients treated with episodic therapy). In addition, a significantly lower rate of abdominal surgical interventions was required in the first group $(2.9 \%$ vs $7.4 \%$, respectively). This data suggests that healing of bowel lesions obtained after infliximab infusion results in lower complication rates. The endoscopic ACCENT 1 substudy (Ruutgers et al 2004) showed that $44 \%$ of patients with colonic ulcers treated with mainteinance doses had complete mucosal healing after 1 year compared with $18 \%$ of patients treated with episodic $5 \mathrm{mg} / \mathrm{kg}$ of infliximab. Patients with persistent complete healing did not require any hospitalization or surgery. Finally, the reported incidence of intestinal obstruction was similar in patients treated with repeated infusions of infliximab and in those treated with placebo. While it was not stated in the ACCENT 1 substudy, to our knowledge, the presence of significant and symptomatic intestinal stenoses was one of the exclusion criteria for the study.

Similary, Witthoft and Ludwig (2005) analyzed continued therapy with infliximab. The patients received 567 infusions (420 re-infusions): $46 \%$ had chronic active CD, $15 \%$ fistulas and $38 \%$ both symptoms. After treatment, $47 \%$ of patients discontinued steroids, and 33\% reduced steroid use; $73 \%$ had very good efficacy with the treatment. De Ridder and colleagues (2004) used infliximab in a pediatric cohort of 30 patients with refractory $C D$, with up 
to 30 infusions. Six patients reported a "good, long-term response"; nearly $53 \%$ of all patients experienced an effective benefit.

Finally, although it has been fully demonstrated that treatment with infliximab can be effective in obtaining the healing of mucosal ulcers, this can not modify the thickness of the intestinal wall in patients with almost fibrotic stenoses (Figure 1). For this reason, in our opinion, the role of such therapy in reducing the need for surgery in patients with symptomatic stenosis has still to be evaluated.

\section{Fistulizing CD}

Infliximab has been found to be effective in the management of entero-cutaneous or perianal fistulae associated with CD. In the first placebo-controlled trial of 94 patients (Present et al 1999), mostly with perianal fistulae, closure of at least half of the fistulas (primary endpoint) occurred in $68 \%$ and complete closure occurred in $55 \%$ of the 63 patients receiving $5 \mathrm{mg} / \mathrm{kg}$ or $10 \mathrm{mg} / \mathrm{kg}$ of infliximab at 0,2 , and 6 weeks; however $10 \%$ developed an abscess at the fistula site, probably since the skin closure occurred without track closure. In this study, the success was defined by the Authors as the absence of perianal secretions, despite "gentle finger compression"; but this may not necessarily correspond with healing of the fistula.

Another recent study (Topstad et al 2003) showed that preinfusional surgical treatment and maintainance immunosuppression improve the healing rate in fistulizing anorectal CD. In particular, intravenous infusion of infliximab following abscess drainage and seton placement resulted in complete clinical response in $67 \%$ of patients with perianal fistula.

In another study from Mount Sinai Hospital (Toy et al 2000), $79 \%$ of the 38 patients treated with intravenous infusion of infliximab for abdominal or perianal draining fistulas, had improvement in pain and drainage while 39\% had closure of the fistulas. However, 10 of the 38 patients needed operation for complete bowel obstruction within 10 weeks after the infusion; four of them had previously known strictures. The conclusion was that the treatment has to be used cautiously in patients with possible or documented strictures.

Another small study by Poritz and colleagues with 28 patients (2002), reported that up to "seventy-three percent of the patients" with fistulizing CD "either required surgery or still had open fistulas after therapy", thus concluding that the use of infliximab does not abolish the need of surgical therapy.

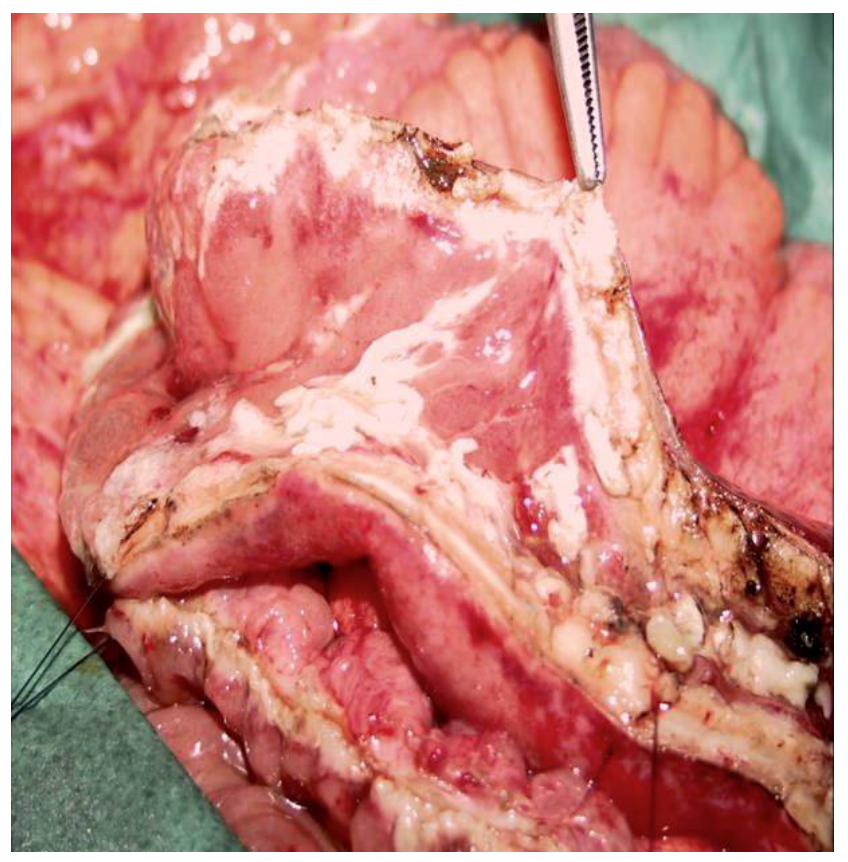

Figure I Healed mucosa but still thickened intestinal wall in patient previously submitted to intravenous infusion of infliximab. A strictureplasy is performed due to persisting obstructive symptoms.

Completely different data have however been reported by Lichtenstein and colleagues (2002) and Weinberg and colleagues (2002). Lichtenstein evaluated the development of symptomatic intestinal strictures in patients prospectively followed in the ACCENT 1 study. No significant increase was found in the incidence of symptomatic strictures in patients receiving the higher aggregate amounts of infliximab. The second study evaluated a large cohort of patients with known intestinal strictures compared to patients who received infliximab but did not have strictures. In this study none of the patients with known strictures had subsequent complete bowel obstruction. These patients, however, were found to be less likely to respond to infliximab, maybe due to end-stage disease that does not have an important inflammatory component.

The ACCENT II study (Sands et al 2004) showed the clinical benefit of maintenance treatment with infliximab in patients with fistulizing $\mathrm{CD}$ who had responded to the induction regimen. In this study patients responders to an initial dose of $5 \mathrm{mg} / \mathrm{kg}$, were randomized at 14 weeks to 8 weekly intravenous infusions of infliximab $5 \mathrm{mg} / \mathrm{kg}$ or placebo. Patients receiving infliximab experienced a significantly prolonged time to loss of response (primary endpoint) compared with that in the placebo group (median 40 vs 14 weeks, $p<0.001)$. At week $54,36 \%$ of patients treated with infliximab had complete absence of draining fistulas compared with $19 \%$ of those treated with placebo maintenance. Similarly to ACCENT 1, maintenance 
infliximab was associated with significant decrease of hospitalizations and CD-related surgeries. Data from ACCENT II study were recently analyzed (Sands et al 2006) to determine whether fistula-related abscess development is affected by fistula exposure. In this study, patients were divided in two groups: the first group treated with infliximab and the second with placebo. Differences in rate of development of fistulas were analyzed by physical examination or by imaging procedures. There were no significant differences between the two groups, with an incidence of newly developed fistula-related abscess in 15\% of patients treated with infliximab against $19 \%$ in the placebo-treated group. These results suggest that fistulizing $\mathrm{CD}$ is not dependent on infliximab exposure.

Similarly, in a recent study, Lichtenstein and colleagues (2005), evaluated 282 patients with fistulizing CD, and found significantly decreased mean hospital stay (0.5 vs 2.5 days), mean number of hospitalizations (11 vs 31), and decreased number of major surgical procedures in patient submitted to infliximab maintenance treatment compared with those who received placebo maintenance. Some concerns, however, arise after the analysis of the results. Firstly, the number of fistula-related surgical procedures, such as drainage and seton placement, extracted from the overall number of nonmajor surgeries is similar between placebo and infliximab groups (49 vs 40, respectively). In addition, mean hospitalization is reported as significantly lower in infliximab group, but no mention is made about the type of treatment required during the hospitalization period. Finally, location of disease is not specified.

\section{Safety issues}

Even if the incidence of adverse events is reported as relatively low in the premarketing trials, recent studies on larger groups of patients have better defined the safety aspects of infliximab therapy.

\section{Serious infections}

Infectious complications related to impairment of the host response represent a common concern for all immunosuppressive therapies. Data from literature show that the risk of sepsis and opportunistic infections seems to be higher in patients already submitted to high-dose steroids and immunosuppressive treatment. The rate of serious infections in clinical trials on CD, however, is not significantly higher in patients treated with infliximab compared with those treated with placebo (6.2 vs $6.8 \%$ respectively) (Rutgers et al 2004). Respiratory and urinary tract infections are the most common infections reported (Siddiqui and Scott 2005).

However, a higher need for antibiotic therapy for infectious complications in patients receiving infliximab versus placebo group ( $32 \%$ vs $22 \%$, respectively) is reported (Remicade PI 2001; Warris et al 2001). Preliminary data from the START trial in patients with rheumatoid arthritis have shown the risk of serious infections with infliximab $3 \mathrm{mg} / \mathrm{kg}$ to be similar to placebo, while $10 \mathrm{mg} / \mathrm{kg}$ was associated with a higher relative risk than placebo (Westhovens et al 2005). Some cases of opportunistic infections, such as aspergillosis and listeriosis have been reported (Remicade PI 2001; Alderson et al 2005). In addition, a large cohort study (Colombel et al 2004) evaluating short and long-term safety of infliximab in 500 consecutive patients with $\mathrm{CD}$ treated at the Mayo Clinic showed that infliximab-related infections occurred in $8.2 \%$ of patients. Twenty patients had serious infections, including 2 with fatal sepsis, 2 with fatal pneumonia, 6 with viral infections, 2 with intraabdominal abscess, and one cellulitis and histoplasmosis, respectively. Colombel and colleagues concluded that even if infliximab is generally well tolerated, "clinicians must be vigilant for the occurrence of infrequent but serious events".

\section{Malignancies}

Long-term follow-up is needed to assess whether or not there is an increased risk of lymphoma or other malignancies. To date, non-Hodgkin lymphoma has been reported in only 3 patients treated for $C D$ and 4 for rheumatoid arthritis (Bickston et al 1999; Remicade PI 2001; Sachmechian et al 2001), and all events occurred in patients already submitted to concomitant immunosuppression. However, the well known trend of CD patients to develop lymphoma and the high rate of lymphomas in immunosuppressed population justify the need for epidemiologic studies to investigate this likely association.

The risk of other malignancies does not seem to be higher. Kane and Reddy (2004) analyzed the prevalence of abnormal Pap smears in 68 women with CD treated with infliximab. There were no cancers and the risk of an abnormal Pap smear was not related to the use of infliximab. However, Chen and colleagues (2006) recently reported a case of hepatocellular carcinoma occurring in a noncirrhotic CD patient who had been treated with both azathioprine and infliximab. Whether infliximab directly or indirectly enhanced susceptibility to the development of hepatocellular carcinoma in this patient is not known, but it is possible 
that infliximab may be a contributing factor in its pathogenesis.

\section{Neurological adverse events}

Infliximab has been associated with rare cases of new onset or exacerbation of clinical symptoms or radiographic evidence of demyelization disorders such as multiple sclerosis and optic neuritis (Wiendl and Hohlfeld 2002; Thomas et al 2004; Enayati et al 2005).

A recent study on 7988 patients with CD and 12185 with ulcerative colitis showed a higher incidence of demyelinating diseases among patients with inflammatory bowel disease. Further studies are needed to clarify the real effect of anti-TNF- $\alpha$ therapy (Gupta et al 2005).

\section{Polmonary adverse events}

Reactivation of latent tuberculosis is a frightening risk of anti-TNF- $\alpha$ therapy. Active tuberculosis has been found in 350 out of 400000 patients treated. Most cases occurred within 2 months after first infusion (Keane et al 2001). Tubercolin skin testing and chest radiograph in patients with positive skin test are recommended (ATS 2000) to initiate appropriate antitubercular therapy before infliximab treatment.

\section{Infusion-related events}

Infusion-related events are common within 1-2 hours after an infusion in approximately $20 \%$ of patients. The most common events are fever and chills, cardiopulmonary symptoms, and urticaria/pruritus (Centocor 2005a, 2005b). Serious events, such as anaphylaxis occur in $<1 \%$ of infliximab recipients. These adverse events can be controlled with drugs (antihistamines or steroids), by slowing down the infusion rate or by discontinuation of infliximab. Repeated infusions are not associated with an increase in the incidence of reactions.

\section{Immunogenic reactions}

Treatment with infliximab could be complicated by production of autoantibodies and antibodies to drug.

The formation of antibodies anti-infliximab (ATI) has been reported in $13 \%$ of patients treated in clinical trials (Remicade PI 2001). However, the detection of antibodies depends on the sensitivity and the specifications of the essay used (Rutgeers et al 2005). Baert and colleagues (2003) found antibody to infliximab (ATI) in $61 \%$ of patients, while Farrel and colleagues (2003) reported an incidence of $36 \%$, using the same essay. These studies demonstrated that the formation of ATI is associated with the occurrence of infusion reactions and with shorter duration of response, while it was decreased by concomitant immunosuppressive therapy.

Vermeire and colleagues (2003) found an incidence of $56.8 \%$ after 24 months of treatment, with antibodies still present one year after last infusion. In two patients an infliximab-related lupus eritematosus occurred. Vermiere reported an association between formation of antibodies and female gender.

Acute reactions are generally easily managed by interrupting infusion and administration of hydrocortisone. Prophylactic anthistamine and hydrocortisone can prevent further reactions.

Severe serum sickness-like reactions, with fever, rash, headache sore throat, myalgia, facial edema and dysphagia, are often associated with episodic treatment, especially after a long drug-free period (Kugathasan et al 2002; Vermeire et al 2003). Symptoms are treated with intravenous or oral steroids at high doses.

\section{Local treatment}

To minimize the risks and to allow the treatment with infliximab even in patients with perianal CD and associated bowel strictures, Lichtiger (2001) had recently proposed the local injection of anti-TNF-a as an alternative to systemic infusion. The rationale for using such technique is based on the evidence, as discussed above, that clinical efficacy of infliximab is due to local anti-inflammatory and immunomodulatory effects in the bowel mucosa, by means of down-regulation of the adhesion molecules within the lamina propria (Cornillie et al 2001). Hence, infiltration of the antibody through the mucosal barrier should enhance its effectiveness.

Lichtiger (2001) reported his experience with 9 patients with mild to moderate perianal disease refractory to antibiotics or 6-MP, treated with a circumferential and intrafistulous injection of infliximab at 0,4 , and 7 weeks. He reported complete healing of the fistula tract in 50\% of patients within 3 weeks; 33\% had a partial response and $17 \%$ did not respond to the treatment. Based on this experience, we have started using this treatment with a modified technique (Poggioli et al 2005), which may contribute to improved results. Specifically, the injection of the drug at the internal orifice allowed the closure of the entire fistulous tract, avoiding false closures limited to the external opening which could lead to new abscess development. 
All patients were treated under general or spinal anaesthesia. Visual inspection, palpation and exploration with probes were performed in order to identify all the fistulous tracts and abscesses; purulent material was drained and the fistula tracts curetted. If necessary, necrotic and inflamed tissues were excised at each operation. Draining setons previously placed in the fistulous tract were removed at the time of the first infusion.

An injection of $15 \mathrm{mg}$ to $21 \mathrm{mg}$ of infliximab, diluted in $10-14 \mathrm{cc}$ of $5 \%$ glucose solution, was then carried out circumferentially at the level of the internal orifice and subsequently in the wall of the fistula tract up to the external orifice. This was done in all fistulas. For all patients we scheduled at least six treatments at $0,4,8,12,16$, and 20 weeks, respectively.

At each subsequent treatment, before infliximab injection, the efficacy of the treatment was assessed separately by two of the Authors (Poggioli and Laureti) by means of a complete examination of the perineum, using a 4 grade personal score (PS) system as follows: grade $1=$ unchanged; grade $2=$ sepsis control, but persisting pus discharge from fistulas; grade $3=$ no pus discharge, no granulation tissue; grade $4=$ closure with scar tissue (tested with probe examination).

We have treated 31 patients to date with a diagnosis of CD and complex perianal fistulas (Sandborn et al 2003) with local injection of infliximab.

The indication for treatment was the presence of complex perianal disease in which the fistula was not controllable by means of medical therapy, seton drainage, fistulotomy, or removal of the fistula tract.

Mean follow-up was 40.6 months (range 3-54 months). No major adverse events were reported. Five patients reported a sensation of heaviness at the injection site for 56 days.

Forty-four patients had concomitant small bowel disease.

Among them, 38 patients had coexisting intestinal fibrostenosing $\mathrm{CD}$ and were therefore not suitable for intravenous infliximab. In this group, $79.0 \%$ healed their fistulas after 6 to 14 injections, reaching grade 4 of PS. Seven patients reached grade 3 after 3 to 5 infusion and are still in treatment. One patient developed recurrent fistula 14 months after last injection and has been recently submitted to redrainage and 2 local injections of infliximab.

Six additional patients with small bowel disease not responsive to previous treatment with intravenous infliximab underwent local injection; only three of them had complete closure of the fistula tracts (grade 4).
Five patients had associated severe colo-proctitis: three had poor results (grade 2) and underwent total abdominal colectomy with Brooke ileostomy and Hartmann's pouch. The remaining 2 patients reached grade 3 of the score after 7 and 9 injections respectively.

The results from our pilot study show that local injection of infliximab is safe and feasible. There were no major adverse events and only one third of the patients reported minimal perianal discomfort after the treatment.

Although the analysis of the results and of the value of our conclusions is limited by the small sample size and the absence of a control group, our experience suggests that local injection could be effective in patients with aggressive perianal disease not treatable with surgery alone and unable to receive intravenous infusion of infliximab. Certainly, further experience with prospective studies is needed, using controls which include no infliximab as well as placebo injection. Moreover, further studies are required in order to evaluate the need of a maintenance treatment once grade 4 of PS is obtained.

Finally, the assessment of the success rate is controversial. In fact, the variety of results reported in the literature is probably due to the lack of agreement between the investigators on clinical assessment. Recently, a misclassification of patients with perianal disease using examination under anesthesia (EUA) alone up to $10 \%$ was reported (Spencer et al 1998; Beets-Tan et al 2001; van Assche et al 2003); in fact, apparent clinical closure of fistulas sometimes is associated with ultrasound evidence of persistence (Poritz et al 2002).

The usefulness of association of magnetic resonance imaging with EUA has been recently emphasized (Sandborn et al 2003). As highlighted by some authors (Schwartz et al 2001; van Assche et al 2003) this technique seems promising since it offers objective criteria of "true" fistula healing, after intravenous infusion and local injection of infliximab; the experience with this procedure, however is limited and needs skilled radiologists in order to rule out false closures (Bell et al 2003).

\section{Conclusions: guidelines for the use of infliximab}

Based on data available to date in the literature, intravenous therapy with infliximab is indicated in selected cases, as follows:

- Patients with moderate to severe CD who demonstrate persisting symptoms or intolerance to conventional 
therapy (steroids and immunosuppressors), or are unable to tolerate such therapies.

- Patients with fistulizing CD, entero-cutaneous, perianal, entero-vesical or entero-vaginal.

The initial dose with three infusions, at weeks 0,2 , and 6 allows obtaining a higher remission rate. Patients who do not responde to three infusions should not receive further infliximab administration.

If no contraindications exist, patients should receive concomitant immunosuppressive therapy in order to reduce formation of antibodies and likelihood of reactions and obtain higher response rates. Concomitant immunosuppression is indicated even in those patients who did not respond to previous treatment.

Regular repeat doses every 8 weeks are effective in maintaining clinical response after induction; although further studies are required to obtain more definitive data about the safety of long-term treatment with infliximab.

Absolute contraindications are:

- Patients with known active infection.

- Patients with central nervous system demyelinating syndromes.

- Patients with class III-IV congestive heart failure.

- Underlying abscess.

- Positive TB skin test.

Infliximab should be used with caution in patients with:

- Significant intestinal obstructive symptoms or documented fibrotic intestinal stenosis without clinical or biochemical evidence of CD activity.

- Current or previous malignancies.

- Pregnancy or lactation.

Finally, local injection of infliximab for the treatment of perianal CD in selected cases is safe and feasible. This treatment could represent an effective option for those patients with perianal fistulas who cannot undergo intravenous infliximab treatment especially if there is associated stenosing ileal CD.

However, further randomized studies are needed to evaluate the effectiveness and the correct indications for this technique.

\section{References}

Alderson JW, van Dinter Jr TG, Opatowsky MJ, et al. 2005. Disseminated aspergillosis following Infliximab therapy in an immunosuppressed patient with Crohn's disease and chronic hepatitis C: a case study and review of the literature. Med Gen Med, 7:7.

[ATS] American Thoracic Society, Centers for Disease Control and Prevention. 2000. Council of the infectious disease society of America, September 1999. Am J Respir Crit Care Med, 161:1376-95.
Baert F, Noman M, Vermeire S, et al. 2003. Influence of immunogenicity on the long-term efficacy of infliximab in Crohn's disease. $N$ Engl J Med, 348:601-8.

Beets-Tan RG, Beets GL, van der Hoop AG, et al. 2001. Preoperative MR imaging of anal fistulas: does it really help the surgeon? Radiology, 218:75-84

Bell SJ, Halligan S, Windsor ACJ, et al. 2003. Response of fistulating Crohn's disease to infliximab treatment assessed by magnetic resonance imaging. Aliment Pharmacol Ther, 17:187-93.

Bickston SJ, Lichtenstein GR, Arseneau KO, et al. 1999. The relationship between infliximab treatment and lymphoma in Crohn's disease. Gastroenterology, 117:1433-37.

Breese E, Michie C, Nicholls S, et al. 1994. Tumor necrosis alphaproducting cells in the intestinal mucosa of children with inflammatory bowel disease. Gastroenterology, 106:1455-66.

Brooklyn TN, Dunnill MG, Shetty A, et al. 2006. Infliximab for the treatment of Pyoderma Gangrenosum: a randomised, double blind, placebo controlled trial. Gut, 55:505-9.

Centocor Inc. 2005a. Product information (EU): Remicade 100mg powder for concentrate for solution for infusion (infliximab $100 \mathrm{mg}$ vial) [online]. Accessed 10 May 2005. URL: http://www.emea.eu.int.

Centocor Inc. 2005b. Product information (US): Remicade for IV injection (infliximab 100mg vial) [online]. Accessed 10 May 2005. URL: http:/ /www.remicade.com.

Chen SC, Cummings OW, Hartley MP, et al. 2006. Hepatocellular carcinoma occurring in a patient with Crohn's disease treated with both azathioprine and infliximab. Dig Dis Sci, 51:952-5.

Colombel JF, Loftus EV, Tremaine WJ, et al. 2004. The safety profile of Infliximab in patients with Crohn's disease: the Mayo Clinic experience in 500 patients. Gastroenterology, 126:19-31.

Cornillie F, Shealy D, D'Haens G, et al. 2001. Infliximab induces potent anti-inflammatory and local activity, but no systemic immune suppression in patients with Crohn's Disease. Aliment Pharmacol Ther, $15: 463-73$

de Ridder L, Escher JC, Bouquet J, et al. 2004. Infliximab therapy in 30 patients with refractory pediatric crohn disease with and without fistulas in The Netherlands. J Pediatr Gastroenterol Nutr, 39:4652 .

Derkx B, Taminiau J, Radema S, et al. 1993. Tumor-necrosis-factor antibody treatment in Crohn's disease. Lancet, 342:173-4.

Enayati PJ, Papadakis KA. 2005. Association of ant-tumor necrosis factor therapy with the development of multiple sclerosis. J Clin Gastroenterol, 39:303-6.

Farrell RJ, Alshahli M, Jeen YT, et al. 2003. Intravenous hydrocortisone premedication reduces antibodies to infliximab in Crohn's disease: a randomized controlled trial. Gastroenterology, 124:917-24.

Gupta G, Gelfand JM, Lewis JD. 2005. Increased risk for demyelinating diseases in patients with inflammatory bowel disease. Gastroenterology, 129:819-26.

Hale S, Lightman S. 2006. Anti-TNF therapies in the management of acute and chronic uveitis. Cytokine, 33:231-7.

Hanauer SB, Feagan BG, Lichtenstein GR, et al. 2002. Maintenance Infliximab for Crohn's Disease: the ACCENT I randomized trial. Lancet, 359:1541-9.

Hanauer SB. 2003. Inflammatory bowel disease: epidemiology, pathogenesis, and therapeutic opportunities. Inflam Bowel Dis, 12(Suppl 1):S3-S9.

Jois RN, Leeder L, Gibb A, et al. 2006. Low-dose infliximab treatment for Ankylosing Spondylitis: clinically and cost-effective. Rheumatology (Oxford), 45:1566-9.

Kane SV, Reddy D. 2004. Infliximab does not increase the risk of abnormal Pap smears in women. Am J Gastroenterol, 99:S246.

Keane J, Gershon S, Wise RP, et al. 2001. Tubercolosis associated with infliximab, a tumor necrosis factor alpha-neutralizing agent. $N$ Engl $J$ Med, 345:1098-104

Kleyn CE, Griffiths CE. 2006. Infliximab for the treatment of psoriasis. Expert Opin Biol Ther, 6:797-805. 
Kugathasan S, Levy MB, Saeian K, et al. 2002. Infliximab retreatment in adults and children with Crohn's disease: risk factors for the development of delayed severe systemic reaction. Am J Gastroenterol, 97:1408-14.

Lichtenstein GR, Olson A, Bao W, et al. 2002. Infliximab treatment does not result in an increased risk of intestinal strictures or obstruction in Crohn's disease patients: ACCENT I study results. Am J Gastroenterol, 97:S254.

Lichtenstein GR, Yan S, Bala M, et al. 2005. Infliximab mainteinance treatment reduces hospitalizations, surgeries, and procedures in fistulizing Crohn's disease. Gastroenterology, 128:862-9.

Lichtiger S. 2001. Healing of perianal fistulae by local injection of antibody to TNF. Gastroenterology, 120(suppl):A3154.

Markham A, Lamb HM. 2000. Infliximab: a review of its use in the management of rheumatoid arthritis. Drugs, 59:1341-59.

Mitoma H, Horiuki T, Hatta N, et al. 2005. Infliximab induces potent antiinflammatory responses by outside-to-inside signals through transmembrane TNF-a. Gastroenterology, 128:376-92.

Nicholls S, Stephens S, Braegger CP, et al. 1993. Cytokines in stools of children with inflammatory bowel disease or infective diarrhea. J Clin Pathol, 46:174-81.

Papadakis KA, Targan SR. 2000. Tumor necrosis factor: biologic and therapeutic inhibitors. Gastroenterology, 119:1148-57.

Poggioli G, Laureti S, Pierangeli F, et al. 2005. Local injection of Infliximab for the treatment of perianal Crohn's disease. Dis Colon Rectum, 48:768-74.

Poritz LS, Rowe WA, Koltun WA. 2002. Remicade does not abolish the need for surgery in fistulizing Crohn's disease. Dis Colon Rectum, 45:771-5.

Present DH, Rutgeers P, Targan S, et al. 1999. Infliximab for the treatment of fistulas in patients with Crohn's Disease. N Engl J Med, 340:1398405 .

Reinecker HC, Steffen M, Witthoeft T, et al. 1993. Enhanced secretion of tumor necrosis factor-alpha IL-6 and IL-1 beta by isolated lamina propria mononuclear cells from patients with ulcerative colitis and Crohn's Disease. Clin Exp Immunol, 94:174-81.

Remicade (Infliximab). 2001. Prescribing information. In: Physician desk reference, $55^{\text {th }}$ ed. Montvale,NJ: Thomson Healthcare, pp 1085-88.

Rispo A, Lembo G, Insabato L, et al. 2004. Successful treatment of therapyresistant metastatic Crohn's disease with infliximab. Br J Dermatol, 150:1045-6.

Robinson DM, Keating GM. 2005. Infliximab: in ankylosing spondylitis. Drugs, 65:1283-91.

Rutgeers P, Van Assche G, Vermeire S. 2004. Optimizing anti-TNF treatment in inflammatory bowel disease. Gastroenterology, 126:1593-610.

Ruutgers P, Feagan BG, Lichtenstein GR, et al. 2004. Comparison of scheduled and episodic treatment strategies of Infliximab in Crohn's disease. Gastroenterology, 126:402-13.

Sachmechian A, Vasiliauskas E, Abreu M, et al. 2001. Malignancy following remicade therapy: incidence and characteristics. Gastroenterology, 120:A619.

Sandborn WJ, Fazio VW, Feagan BG, et al; American Gastroenterological Association Clinical Practice Committee. 2003. Technical Review of Perianal Crohn's Disease. Gastroenterology, 125:1508-30.

Sandborn WJ, Hanauer SB. 1999. Antitumor necrosis factor therapy for inflammatory bowel disease: a review of agents, pharmacology, clinical results, and safety. Inflamm Bowel Dis, 5:119-133.
Sands BE, Anderson FH, Bernstein CN, et al. 2004. Infliximab manteinance therapy for fistulizing Crohn's disease. N Engl J Med, 350:876-85.

Sands BE, Blank MA, Diamond RH, et al. 2006. Maintenance infliximab does not result in increased abscess development in fistulizing Crohn's disease: results from the ACCENT II study. Aliment Pharmacol Ther, 23:1127-36

Scallon BJ, Moore MA, Trihn H, et al. 1995. Chimeric anti-TNF-alpha monoclonal antibody cA2 binds recombinant transmembrane TNFalpha and activates immune effector functions. Cytokine, 7:251-9

Schwartz DA, Wiersema MJ, Norton ID, et al. 2001. A comparison of endoscopic ultrasound, magnetic resonance imaging, and exam under anesthesia for evaluation of Crohn's perianal fistulas. Gastroenterology, 121:1064-72.

Siddiqui MAA, Scott LJ. 2005. Infliximab: a review of its use in Crohn's disease and rheumatoid arthritis. Drugs, 65:2179-208.

Spencer JA, Chapple K, Wilson D, et al. 1998. Outcome after surgery for perianal fistula: predictive value of MR imaging. AJR $A m J$ Roentgenol, 171:403-6.

Targan SR, Hanauer SB, Deventer SJ, et al. 1997. A short-term study of chimeric monoclonal antibody cA2 to tumor necrosis factor alpha for Crohn's disease. N Engl J Med, 337:1029-35.

Thomas CW jr, Weinshenker BG, Sandborn WJ. 2004. Demyelination during anti-tumor necrosis factor alpha therapy with Infliximab for Crohn's disease. Inflamm Bowel Dis, 10:28-31.

Topstad DR, Panaccione R, Heine JA, et al. 2003. Combined seton placement, infliximab infusion, and maintenance immunosuppressives improve healing rate in fistulizing anorectal Crohn's disease: a single center experience. Dis Colon Rectum, 46:577-83.

Toy LS, Scherl EJ, Kornbluth A, et al. 2000. Complete bowel obstruction following initial response to infliximab therapy for Crohn's disease: a series of a newly described complication. Gastroenterology, 118(suppl):A569.

van Assche G, Vanbeckevoort D, Bielen D, et al. 2003. Magnetic resonance imaging of the effects of infliximab on perianal fistulizing Crohn's disease. Am J Gastroenterol, 98:332-9.

van den Brande JMH, Hommes DW, Peppelenbosch MP. 2005. Infliximab induced T lymphocyte apoptosis in Crohn's disease. J Rheumatol Suppl, 74:26-30.

Vermeire S, Noman M, Van Assche G, et al. 2003. Autoimmunity associated with anti-tumor necrosis factor alpha treatment in Crohn's disease: a prospective cohort study. Gastroenterology, 125:32-9.

Warris A, Bjorneklett A, Gaustad P. 2001. Invasive pulmonary aspergillosis associated with Infliximab therapy. $N$ Engl J Med, 344:1099-100.

Weinberg AM, Rattan S, Lewis JD, et al. 2002. Strictures and response to Infliximab in Crohn's disease. Am J Gastroenterol, 97:S255.

Westhovens R, Rahman MU, Han C. 2005. Infliximab treatment results in a rapid improvement in all aspects of quality of life assessed by the sf-36 in patients with Rheumatoid Arthritis: results from the START trial [abstract]. Ann Rheum Dis, 64(Suppl. III):392, FRI0450

Wiendl H, Hohlfeld R. 2002. Therapeutic approaches in multiple sclerosis: lessons fromfailed and interrupted treatment trials. Bio Drugs, 16:183200 .

Witthoft T, Ludwig D. 2005. Effectiveness and tolerability of repeated treatment with infliximab in patients with Crohn's disease: a retrospective data analysis in Germany. Int J Colorectal Dis, 20:18-23. 